\title{
Taxa De Exames Solicitados Por Consulta Ambulatorial Em Hospital Universitário De Porto Alegre
}

\author{
Kipper, C.E.; Butzke, B.L.; Jimenez, L.F.; Marimon, M.M.; Fernandes, V.F.; \\ Citollin-Santos, G.E.; Uzeika, L.; \\ Apresentador: Cristiano Ely Kipper \\ Premiados - Menção Honrosa: Destaque acadêmico
}

\section{Resumo}

Introdução: A solicitação de exames é necessária para o adequado diagnóstico e acompanhamento ambulatorial dos pacientes, porém, quando esta pratica se torna excessiva, há geração de custos para o sistema de saúde, além de exposição do paciente a um maior risco de iatrogenias. $\mathrm{O}$ aumento da taxa de solicitação de exames por consulta é um problema mundial, e as maneiras de conter este fenômeno vem sendo extensamente discutidas na literatura médica. O objetivo deste trabalho é analisar a taxa média de solicitação de exames por consulta ao longo dos meses e ano, de 2004 a 2014 no HCPA. Métodos: Foram analisados dados do Sistema de Indicadores de Gestão do HCPA relacionados ao número de consultas e número de exames solicitados. Analisamos as taxas de solicitação de exames/ consultas ao longo dos meses do ano e seus padrões de variação. Resultados: Durante o período de 2004 a 2014, houve um aumento de 0 a $5 \%$ no número total de consultas anualmente, enquanto o número total de solicitações de exames aumentou 5 a $10 \%$ a cada ano. A taxa de solicitação de exames em 2004 era de 2,62 exames/consulta, aumentando no ano de 2014 para 3,74 exames/consulta, resultando em um aumento total de $42 \%$ na taxa de solicitação média de exames/consulta. A análise dos dados demonstrou um aumento de 8 a 14\% na taxa de solicitação de exames no período de dezembro a fevereiro em comparação com os outros meses do ano. Conclusão: Existem diversos fatores envolvidos no aumenta da taxa de solicitação de exames por consulta ambulatorial, como o envelhecimento da população, com maior prevalência de doentes crônicos, o aumento da prática da medicina defensiva e, no caso do HCPA, a progressiva inclusão de acadêmicos no atendimento ambulatorial sem adequada preceptoria. $\mathrm{O}$ aumento sazonal da taxa de solicitação de exames no período dezembro-fevereiro pode estar refletindo esta prática. Os resultados encontrados neste estudo reforçam a necessidade de alterar esta realidade, através da orientação dos profissionais de saúde, implementação de protocolos e instituição de medidas administrativas, objetivando a solicitação racional de exames.

\section{Referência:}

Kipper, C.E.; Butzke, B.L.; Jimenez, L.F.; Marimon, M.M.; Fernandes, V.F.; Citollin-Santos, G.E.; Uzeika, L.;. Taxa De Exames Solicitados Por Consulta Ambulatorial Em Hospital Universitário De Porto Alegre. In: II Congresso Brasileiro de Medicina Hospitalar - II CBMH [= Blucher Medical Proceedings, vol.1, num.5] São Paulo: Editora Blucher, 2014 . p.5

DOI 10.5151/medpro-II-cbmh-037 